\title{
Proximal Left Anterior Descending Coronary Artery Stenosis
}

National Cancer Institute

\section{Source}

National Cancer Institute. Proximal Left Anterior Descending Coronary Artery Stenosis. NCI Thesaurus. Code C80429.

A narrowing of the proximal portion of the left main coronary artery, usually considered significant if the stenosis is $70 \%$ or greater. 